\title{
Improving the altimetric rain record from Jason-1 \& Jason-2
}

\author{
G.D. Quartly (National Oceanography Centre, Southampton \\ Empress Dock, Southampton, Hants, SO14 3ZH, UK) \\ email: gdq@noc.soton.ac.uk \\ Submitted to J. Geophys. Res. Oceans 27th July 2009; revision 1st Oct. 2009
}

\begin{abstract}
Dual-frequency rain-flagging has long been a standard part of altimetric data analysis, both for quality control of the data and for the study of rain itself, because altimeters can provide a finer spatial sampling of rain than can passive microwave instruments. However, there have been many varied implementations, using different records of the surface backscatter and different thresholds. This paper compares four different measures available for the recently-launched Jason-2. The evaluation compares these measures against clearly desired properties, finding that in most cases the adjusted backscatter and that from the ice retracker perform much better than that recommended in the users' handbook. The adjusted backscatter measure also provides a much better link to observations from Jason-1, opening up a much longer period for consistent rain investigations, and enabling greatly improved analysis of the shortscale variability of precipitation. Initial analysis shows that although the spatial and temporal gradients of backscatter increase at very low winds, the spatial gradients in rain attenuation are concentrated where rainfall is greatest, whilst the temporal changes have a simple broad latitudinal pattern.
\end{abstract}

\section{Introduction}

Precipitation at sea is an important part of the ocean-atmosphere freshwater flux, affecting both the atmosphere and the ocean. The loss of moisture from the air affects its density and hence the atmospheric circulation, as well as changing the potential for downstream precipitation over land. But the density of surface waters are also affected by precipitation, with the possible formation of slicks, with strong vertical stratification. These reduce vertical mixing and decouple the wind-induced surface flow from that deeper down. Also, the reduction in density of surface waters makes them less susceptible to deep convection upon cooling, and thus alters the location and depth to which such convection can occur, potentially changing the whole meridional overturning circulation.

However, despite the many satellite instruments showing some ability to measure rain or the clouds associated with it, it is still hard to provide quantitative records of rainfall. This is on account of the high spatial and temporal variability of the processes relative to the beam footprint of many sensors, and their revisit time, which is determined by the satellites' orbital configuration. Although geostationary infra-red (IR) sensors offer frequent observations at a scale of $\sim 4 \mathrm{~km}$ or better, their measurements of cloud top temperatures are only indirectly related to rain, and consequently usually only used after averaging over large areas [Richards and Arkin, 1981]. On the other hand passive microwave (PM) sensors may detect rain rather than clouds, but only produce an average over a footprint some $30-50 \mathrm{~km}$ across. Given that rain cells may be of order $4 \mathrm{~km}$ in size [Walsh et al., 1984], this means that the PM value is a non-linear average over a number of such cells. Indeed, because of the uncertainties in the modelling of radiative processes and the assumptions involved, there can be great variations between instantaneous satellite estimates of rainfall and ground truth observations [Ebert and Manton, 1998]. This leads to large differences between different satellite-based climatologies [Béranger et al., 2006] and also between composite climatologies and reanalyses from numerical weather prediction (NWP) models [Béranger et al., 2006; Quartly et al., 2007].

In this context, altimetric detection of rain is very useful, despite not being able to provide the frequent global data needed for many applications. First, its large-scale time-average quantitative climatology is based on a different remote-sensing technology from the more common IR and PM instruments, and thus the errors in an altimetric climatology will be largely independent of those in other climatologies. Second, active microwave systems provide finer spatial resolution of rainfall than that offered by IR or PM sensors, and thus information on dominant length scales can be fed back into other 
algorithms e.g. to characterise likely non-uniform beamfilling for PM sensors [Kummerow, 1998[. The Tropical Rainfall Measuring Mission (TRMM, see Kummerow et al., [1998]) is now providing much of this information, but only within the $35^{\circ} \mathrm{S}-35^{\circ} \mathrm{N}$ confines of its orbit.

The technique of estimating rain rate from nadir-pointing dual-frequency altimeters was established more than a decade ago [Quartly et al., 1996]. Many radar altimeters operate at both $\mathrm{K}_{\mathrm{u}}$-band $(13.6 \mathrm{GHz})$ and at a lower frequency (C-band for TOPEX, Jason-1 \& Jason-2) that was added principally to provide estimates of the ionospheric correction through differences in range estimation [Fu et al, 1994]. However, the additional records of wave height $\left(\mathrm{H}_{\mathrm{s}}\right)$ and backscatter $\left(\sigma^{0}\right)$ at these two frequencies have proven very useful, especially providing realistic wave height and wind speed data across storms [Quartly, 1997; Quartly and Guymer, 2007] when data from the primary frequency is compromised through partial attenuation by intervening raindrops. Figure 1 shows the differences in backscatter values for TOPEX i.e. $\sigma_{\mathrm{Ku}}^{0}-\sigma_{\mathrm{C}}^{0}$ as a function of $\sigma_{\mathrm{C}}^{0}$ (as C-band is the frequency less affected by rain), with departures from the narrow envelope being associated with rain [Quartly et al., 1996].

The $\sigma^{0}$ values for TOPEX were determined as a simple summation over the power in each bin of the waveform [Marth et al., 1993], whereas for its successor, Jason-1, a modelled waveform was fitted and used to determine the signal strength (see Fig. 2). Extension of dual-frequency rain altimetry to Jason-1 was initially simple [Quartly, 2004; Tournadre, 2004], since that altimeter operated at the same frequencies as TOPEX. However there was a change in the ground-processing of Jason-1 data to utilize a more complex waveform model fitting four rather than three parameters [Amarouche et al., 2004[. This extra term, $\psi^{2}$, is conceptually related to the square of the mispointing angle, but as the value $\psi^{2}$ is estimated from changes in the slope of the waveform trailing edge it may actually be positive or negative. Its inclusion led to marked changes in the clustering of $\sigma^{0}$ values at the two frequencies, and thus prompted the suggestion that flagging should instead be implemented using the values output by the Automatic Gain Control (AGC, see Tournadre [2006a]). The AGC is a measure of the attenuation placed in the receive line prior to the detection of the waveforms and thus an indicator of the expected rather than observed signal strength.

A further $\mathrm{K}_{\mathrm{u}} / \mathrm{C}$-band altimeter, Jason-2 was launched on 20th June 2008, and placed in an orbit $55 \mathrm{~s}$ behind Jason-1. The routine ground processing for Jason-2 offered an extra measure of backscatter

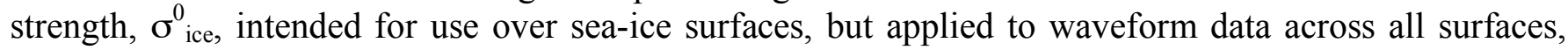
including the open ocean. The difference between the output of the ocean and ice retrackers (averaged down from $20 \mathrm{~Hz}$ records to $1 \mathrm{~Hz}$ ) is mostly a simple linear function of $\psi^{2}$ (Fig. 2).

Thus there are a number of different measurements of backscatter that may be used for implementing dual-frequency rain-flagging for the Jason altimeters. This paper looks at four different measures: $\sigma^{0}, \mathrm{AGC}$ and $\sigma^{0}$ ice introduced previously plus an 'adjusted value', $\sigma_{\text {adj }}^{0}$, introduced by Quartly [2009a]. The aim of this paper is to determine which measure is the most appropriate to use for dualfrequency rain-flagging, with a view towards developing an accurate and consistent technique across more than one altimetric mission. The source of altimeter data and its processing is introduced in section 2 , and a brief discussion of the dual-frequency technique and its evaluation given in section 3 . These four measures of backscatter are then evaluated in section 4, and section 5 looks at the added information on rain from using multiple altimeters. Conclusions, with a recommendation for routine implementation are presented in the final section.

\section{Data source and processing}

The main dataset used here is the interim geophysical data records (IGDR) for the Jason-2 altimeter. Jason- 2 was the first of the $\mathrm{K}_{\mathrm{u}} / \mathrm{C}$-band altimeters to have $\sigma^{0}{ }_{\text {ice }}$ readily available for evaluation over the ocean, and this paper concentrates on the calibration phase when its orbit was 55 seconds behind that of its predecessor Jason-1, which allows comparisons between the two satellites. During this 6.5month period (4th July 2008 to 26th Jan. 2009), the data were provided with an initial calibration that has subsequently been revised; the important thing is that this set of data are fully consistent. As dual- 
frequency rain-flagging is developed through internal consistency of the dataset, an absolute calibration is not required. The Jason-2 orbit gives complete Earth coverage between $66^{\circ} \mathrm{S}$ and $66^{\circ} \mathrm{N}$ every cycle of 9.9156 days; just over 20 such cycles of data are available for the calibration phase.

In order to quantify precisely the effect of rain, data were restricted to $55^{\circ} \mathrm{S}-55^{\circ} \mathrm{N}$ (to avoid sea-ice) and points for which the radiometer flag was set to ocean (to avoid land affecting either the altimeter or radiometer measurements). The radiometer on the platform operates at three frequencies $(18.7,23.8$ and $34.0 \mathrm{GHz}$ ); here the integrated liquid water content, $\mathrm{LWC}$, is used, with a threshold of $0.4 \mathrm{~kg} \mathrm{~m}^{-2}$ being considered suggestive of probable rain; this flags $\sim 4.5 \%$ of points. [For the Topex Microwave Radiometer, $0.6 \mathrm{~kg} \mathrm{~m}^{-2}$ was regarded as likely to be associated with rain (Cailliau and Zlotnicki, 2000); thus the value used here is a more conservative choice to discard cases where light rain might be possible.] The determination of Jason-1/Jason-2 match-ups to within $1 \mathrm{~km}$ is detailed in section 4.4.

The fourth measure of backscatter, $\sigma_{\text {adj }}^{0}$, is designed to compensate for poor conditioning of the geophysical model [Challenor and Srokosz, 1989] that leads to correlated errors in the estimation of $\sigma^{0}$ and $\psi^{2}$. The adjustment recommended by Quartly [2009a] is:

$$
\sigma_{\text {adj }}^{0}=\sigma^{0}-\alpha\left(\psi^{2}-\psi_{\text {lo }}^{2}\right)
$$

where $\psi^{2}$ and $\psi_{\text {lo }}^{2}$ are in units of $\mathrm{deg}^{2}$, and $\psi_{\text {lo }}^{2}$ is the long-term mean of $\psi^{2}$, and the proportionality constant $\alpha$ is 11.34 for $\mathrm{K}_{\mathrm{u}}$-band and 2.01 for C-band. The term $\psi^{2}$ lo corresponds to the actual instrument mispointing which should only vary slowly over a fraction of an orbit. For Jason-2 the platform attitude is very stable, and so $\psi_{\text {lo }}^{2}$ may be simply replaced by the mean value 0.0122 . [Again, a later calibration may change the values of $\psi^{2}$ and thus this mean, but it is only the variations about this mean that concern us.]

\section{Recap on aims of dual-frequency rain-flagging}

Observations have shown that the backscatter recorded at $\mathrm{K}_{\mathrm{u}}$-band and that recorded at C-band are generally highly correlated, as both measures are principally responding to changes in wind speed (the higher the wind speed, the lower the reflectance at nadir). Thus the set of points free from land, sea-ice and rain can be used to define an expected envelope of where wind-only points will lie. The key properties are the mean relationship and the scatter about it (expressed as std. dev. in each narrow $\sigma^{0}{ }_{C}$ bin). Then for all observations (including rain-affected ones) a sigma0 anomaly can be defined as how far points lie above/below this mean curve. In the case of rain, these departures from the mean relationship are attributed to attenuation by liquid water droplets throughout the atmospheric column. That explanation is confirmed by the fact that data flagged in such a manner correspond to significant integrated liquid water content (LWC) as shown by a co-manifested microwave radiometer [Quartly et al., 1996; Tournadre and Morland, 1997], and to active rain cells as shown by ground-based radar [McMillan et al., 2002]. This paper concentrates on the $1 \mathrm{~Hz}$ backscatter data, which provide values every $\sim 5.6 \mathrm{~km}$ along track; to achieve higher resolution retrievals requires analysis of the full waveform data [Tournadre, 1998; Quartly, 1998].

In the context of comparing four different backscatter measures for Jason-2, there are a number of favourable aspects to look for. First the mean relationship must be well-defined, and preferably smoothly varying so that a simple interpolation or extrapolation can be justified to cover all possible observations. Second, this mean relationship should not vary much with time. There may be gradual changes as the instrument ages; however for earlier work with TOPEX separate means were calculated for each 10-day cycle [Quartly et al., 1996; Tournadre and Morland, 1997]. It would be convenient, especially for near real-time applications, if a mean determined over the calibration phase could be used for many subsequent cycles of data. Third, the attenuation caused by rain is roughly proportional to rain rate (see Fig. 2 of Quartly et al. [1999]), with a rain rate of $2.3 \mathrm{~mm} \mathrm{hr}^{-1}$ leading to a reduction in $\sigma_{\mathrm{Ku}}^{0}$ of $0.5 \mathrm{~dB}$. Thus to detect low rain rates reliably requires that the envelope of wind-only points be as tight as possible i.e. that the standard deviation about the mean is small. 
The whole purpose of defining a rain-flag is that it should be able to respond to rain cells the size of an altimetric footprint (of order $12 \mathrm{~km}$ in diameter, depending upon definition). A thorough validation is difficult because of the lack of simultaneous high-resolution data. Cailliau and Zlotnicki [2000] performed the first validation of TOPEX's rain-flagging using Special Sensor Microwave/Imager (SSM/I) data, and showed promising agreement despite the coarse resolution of the passive microwave instrument. McMillan et al. [2002] used four different sets of ground-based rain radar data to perform a higherresolution validation, although the number of simultaneously observed rain events was still small. The current paper makes two comparisons - firstly with the simultaneous passive microwave data available from the Jason-2 satellite (although the effective resolution of LWC records is $\sim 25 \mathrm{~km}$ ), and secondly by contrasting the geographical patterns of detected rain against AMSR-E data for the same period. (The Advanced Microwave Scanning Radiometer is a passive microwave radiometer with somewhat better resolution than SSM/I.) A further evaluation may be achieved by comparing the rain records for Jason-2 with those of Jason-1 taken only $55 \mathrm{~s}$ earlier. Clearly this does not test for errors in the underlying physical model, but the consistency (or lack of it) puts bounds on our confidence of using a particular measure.

The preceding evaluations looked at the ease of implementation and how the flagged pixels matched with other indicators of rain. A final evaluation is of how effective a scheme is for removing 'problem data' i.e. those characterised by anomalous spikes in sea surface height or wave height. The removal of suspect values is one of the key drivers of altimetric rain-flagging, but for such an application it does not matter whether the flagged data are actually affected by rain, sea-ice or surface slicks. For example, the implementation of dual-frequency flagging of Envisat data by Lillibridge et al. [2004] simply discards rare $\sigma^{0}$ pairings whatever their cause. The indicators to be used here are simply what percentage of data are discarded and whether they correspond to suspect values in other parameters.

Table 1 details the mean values for each of the four measures calculated from the Jason-2 IGDR data for cycles 002 to 020 . In this paper, offsets are added to measures 2 to 4 to give the same means as $\sigma^{0}$; this makes the display and discussion of differences simpler. It is worth noting in passing that the mean offset between $\sigma^{0}$ ice and $\sigma^{0}$ is a very simple function of $\psi^{2}$ (see Fig. 2), with the displacements roughly proportional to $\psi^{2}$ and with the coefficients used in Eq. 1. Note, however, that at C-band the offset is also a function of $\sigma^{0}$ (Fig. 2c) and that for both frequencies the offset does change slightly with wave height, $\mathrm{H}_{\mathrm{s}}$ (not shown).

\section{Evaluation of the different rain-flagging measures}

Each of the four measures of backscatter $\left(\sigma^{0}, A G C, \sigma^{0}\right.$ ice, $\left.\sigma_{\text {adj }}^{0}\right)$ was processed in the way illustrated for TOPEX (Fig. 1) to produce a mean curve and std. dev., with processing initially performed separately for each cycle of data. Later examination for more subtle effects was performed on cycles 002 to 020 combined, where the extra data length is needed to produce more statistically meaningful results.

\subsection{Shape of mean curve and consistency}

To a large extent, an increase in wind speed leads to similar enhancements in roughness at a range of scales, and thus the nadir reflections of $\mathrm{K}_{\mathrm{u}}$-band and $\mathrm{C}$-band are similarly affected. Therefore the difference between $\mathrm{K}_{\mathrm{u}^{-}}$and $\mathrm{C}$-band reflectance only changes by a few $\mathrm{dB}$ over a range of wind speeds that cause the individual reflectances to vary by more than $10 \mathrm{~dB}$. The curve for TOPEX (Fig. 1) shows a peak around $\sigma_{C}^{0}=15.1 \mathrm{~dB}$ (corresponding to a wind speed of $6.0 \mathrm{~m} \mathrm{~s}^{-1}$ ) where the surface roughness at scales interacting with $\mathrm{K}_{\mathrm{u}}$-band radiation are most enhanced compared with the scales 2.5 times larger recorded by C-band. For TOPEX this difference in reflectance is $-3.5 \mathrm{~dB}$. The successor satellites, Jason-1 and Jason-2, do not have the same calibration as TOPEX, and thus a similar plot for Jason-2 has a peak at $\sigma_{C}^{0}=15.5 \mathrm{~dB}$ (again corresponding to a wind speed of $6.0 \mathrm{~m} \mathrm{~s}^{-1}$ ) but with a difference $\sigma_{\mathrm{Ku}}^{0}-\sigma_{\mathrm{C}}^{0}$ of $-1.4 \mathrm{~dB}$. 
As all the other measures being evaluated here have been adjusted to have similar means at $\mathrm{K}_{\mathrm{u}}$-band and C-band, their mean curves have peaks at approximately the same location (Fig. 3a). In each case, mean and std. dev. have been calculated in $0.05 \mathrm{~dB}$ bins for 10 to $30 \mathrm{~dB}$, and then a 5-point filter applied to reduce somewhat the large changes at $\sigma_{C}^{0}$ values that are high and comparatively rare. For cycle 011 , the curve for the AGC relationship is clearly different from the others. The mean AGC relationship is a smooth curve for cycle 000 and the first three quarters of cycle 001 ; subsequent cycles show the jagged mean relationship portrayed in green. This is because AGC is not a direct measure of backscatter, but an instrument setting; for the first 15 days Jason-2 was in one particular acquisition mode (using the splitgate tracker); subsequent data were collected in two other modes (median tracker and DIODE/DEM coupled mode) which were designed to reduce the number of small changes in AGC, by using set values for longer.

Separate mean relationships were determined for each of the cycles of data. The difference between successive cycles was calculated, and the r.m.s. of this change is displayed in Fig. 3b. In general, the mean relationship for most measures is almost constant, with r.m.s. changes of $\sim 0.02 \mathrm{~dB}$ when $\sigma_{C}^{0}$ is in the range $14.5-17.5 \mathrm{~dB}$, which corresponds to $90 \%$ of the points. Much greater inter-cycle variation is found at high $\sigma_{C}^{0}$, which is where there are fewer points and the mean relationship is less constrained. The exception to these general comments is AGC, which has much greater variation between cycles.

\subsection{Scatter about mean relationship}

In order to detect the weak altimetric signal of drizzle, it is necessary that the 'cloud' of rain-free observations (as in Fig. 1) be as narrow as possible. This is characterized by the standard deviation about the mean relationship (Fig. 3c). Three of the measures show curves similar in shape to that for TOPEX (Fig. 1). AGC is once again the exception, in that for certain specific AGC_Ku settings, the AGC_C may be set to a fixed value; for intermediate AGC_Ku settings, the setting for AGC_C is more volatile. This emphasises the problem of using a measure that is based upon the predicted rather than the actual signal. The shapes of the other curves have a strong similarity, showing the tightest envelope when $\sigma_{C}^{0}$ is around $15-16 \mathrm{~dB}$. This is close to the peak of the mean curves (Fig. 3a) and the mode of the histogram of $\sigma^{0}{ }_{\mathrm{C}}$ values $(15.1 \mathrm{~dB})$, but neither fact is directly responsible for setting the location of the minimum scatter. Clearly the adjustment process designed to overcome spurious changes in $\sigma_{\mathrm{Ku}}^{0}$ and $\sigma_{\mathrm{C}}^{0}$ [Quartly, 2009a] considerably improves the match of rain-free observations at the two frequencies. The measure $\sigma^{0}$ ice achieves almost the same level of improvement as $\sigma_{\text {adj. }}^{0}$

\subsection{Correspondence with other rain sensors}

Rain-flagging is, of course, intended to detect observations contaminated by rain, and these should show significant correspondence with high levels of integrated liquid water shown by the on-board radiometer. [Note, a perfect correspondence is not expected because the radiometer will only record the larger rain cells on account of the instrument's footprint size.] Figure 4 shows selected histograms of the sigma0 anomaly (i.e. how much the $\mathrm{K}_{\mathrm{u}}$-band measure differs from the mean expected given the contemporaneous value at C-band). All histograms are displayed using logarithmic axes in order to show the detailed behaviour. Typically various sources of instrument noise should yield a Gaussian distribution, which will here map onto a narrow inverted parabola. If rainfall rates are assumed to have an exponential distribution, this will be reproduced by a linear tail on the left-hand side of the histogram. Observations deemed to have 'significant' attenuation should have a high correlation with radiometerderived LWC values exceeding $0.4 \mathrm{~kg} \mathrm{~m}^{-2}$. The epithet 'significant' is typically interpreted as a fixed threshold of -0.5 dB [Quartly et al., 1996; Quartly, 2004] or a set multiple of the std. dev. [Tournadre and Morland, 1997; Tournadre, 2004]. The vertical dotted lines on Fig. 4 show \pm 2 std. dev.

The histogram for AGC (Fig. 4c) sticks out because of its spiky nature. The shape of the histogram cannot be meaningfully interpreted as to the real distribution of rain rates. The histogram for the simple $\sigma^{0}$ measure at moderate winds (Fig. 4a) has a shape similar to that shown for TOPEX (Fig. 11 of Quartly 
et al. [1999]), with sigma 0 anomalies exceeding $-0.8 \mathrm{~dB}$ matching the radiometer on $\sim 72 \%$ of occasions. However, there is a notable number of observations at positive sigma0 anomaly (i.e. $\mathrm{K}_{\mathrm{u}}$-band signal greater than expected) which also correlate with the radiometer. This 'inverse behavior' was noted for TOPEX [Quartly et al., 1996; Chen et al., 1998; Quartly et al., 1999] and attributed to freshwater slicks from recent rain acting to damp small-scale roughness. Some of the significant positive sigma0 anomalies may be due to wave damping by rain. However, for these $\sigma^{0}$ records, it is likely that the majority of points are due to small-scale variability within the altimeter footprint, leading to spurious values of $\psi^{2}$ and $\sigma^{0}$, with this intra-footprint variability due to both rain and inhomogeneities in the wind field. At low winds (high $\sigma^{0}$ ) the correspondence between sigma0 anomaly and radiometer is much poorer (Fig. 4b), with not even a $-2 \mathrm{~dB}$ anomaly matching LWC well. This is because in light winds there is much greater variability in the waveform-derived measure $\psi^{2}$ (Fig. 5). As an erroneous estimate of $\psi^{2}$ leads to commensurate errors in $\sigma_{\mathrm{Ku}}^{0}$ and $\sigma_{\mathrm{C}}^{0}$, the determined sigma 0 anomaly is prone to much greater variations irrespective of whether significant LWC is present. Tournadre et al. [2009] have proposed that rain-flagging for the mono-frequency AltiKa mission be based upon variability in $\psi^{2}$, but because this varies significantly with $\sigma_{C}^{0}$ and not latitude, it is likely that low winds and surface slicks rather than rain will be the main cause of such small-scale variability.

The bottom four panels show the histograms for $\sigma_{\text {adj }}^{0}$ under different wind conditions, with Figs. $4 \mathrm{f}$ $\& 4 \mathrm{~g}$ corresponding to the conditions shown for $\sigma^{0}$ in Figs $4 \mathrm{a} \& 4 \mathrm{~b}$. As well as the narrow distribution (evidenced by the breadth of the peak and the dotted lines which echo information from Fig. 3c), one notes that the high correspondence with LWC occurs for smaller sigma0 anomalies. A major difference is the almost complete dearth of records for a sigma 0 anomaly exceeding the $+2 \mathrm{std}$. dev. threshold. This suggests that the earlier records of 'inverse behavior' associated with radiometer-derived rain clouds may be an artefact of the $\sigma^{0}$ processing of previous altimeters. At even higher $\sigma^{0}$ values (Fig. $4 \mathrm{~h}$ ) the correspondence between radiometer and altimeter records of rain is hard to assess meaningfully. If rainflagging is implemented using $\sigma_{\text {adj }}^{0}$ and a fixed threshold of $-0.5 \mathrm{~dB}$, then at low $\sigma_{\text {adj }}^{0}$ (high winds) $90 \%$ of points correspond to $\mathrm{LWC} \geq 0.4 \mathrm{~kg} \mathrm{~m}^{-2}$, whereas at very low winds only $10 \%$ also pass the LWC test. If, instead, the variable threshold of $2 \mathrm{std} \mathrm{dev}$ is used, points flagged using the altimetry will match the radiometer typically about $35 \%$ of the time, except for extremely low and high $\sigma_{\text {adj }}^{0}$ values. Table 2 details the necessary threshold for altimetric rain-flagging to be matched at least $50 \%$ of the time by LWC exceeding $0.4 \mathrm{~kg} \mathrm{~m}^{-2}$. This threshold for $50 \%$ agreement with LWC is clearly not a fixed value (it ranges from -0.30 to $-0.46 \mathrm{~dB}$ ); at low $\sigma_{C}^{0}$ it corresponds to -2 std. dev., but for higher $\sigma^{0}{ }_{C}$ it is nearly -3 std. dev. Actually, the association of LWC with sigma0 anomaly changes markedly at these values, such that the required anomaly to make a $50 \%$ match with $\mathrm{LWC}>0.6 \mathrm{~kg} \mathrm{~m}^{-2}$ is only a further $0.02-0.04 \mathrm{~dB}$ lower. Given that $\sigma_{\text {ice }}^{0}$ shows a similar scatter about the mean to $\sigma_{\text {adj }}^{0}$ (see Fig. 3c), it is not surprising that its histogram (Fig. 4d) looks very similar to that for $\sigma_{\text {adj }}^{0}$ under the same wind conditions (Fig. 4f). However, there are subtle differences: first the histogram of $\sigma^{0}$ ice shows a higher number of observations of large attenuation (e.g. below $-2.5 \mathrm{~dB}$ ), and second, for $\sigma_{\text {ice, }}^{0}$ positive sigma 0 anomalies have almost no connection with LWC.

The second comparison of rain-flagging with another instrument is done by constructing maps of flagged data. For each of the four measures, data are flagged separately according to whether the associated sigma0 anomaly lies below i) $-0.5 \mathrm{~dB}$ or ii) -2 std. dev. Data were aggregated in $2.5^{\circ} \times 2.5^{\circ}$ boxes spanning the 190 days of cycles 002 to 020 and the proportion of data flagged per box was calculated. Figure 6 a shows an example for the standard $\sigma^{0}$ using the -2 std. dev. threshold. Data are frequently flagged throughout both the intertropical convergence zone (ITCZ) and the Southern Ocean. Figure $6 \mathrm{~b}$ shows the AMSR record of the frequency of rain at rates exceeding $1 \mathrm{~mm} \mathrm{hr}^{-1}$ (i.e. drizzle or heavier). This does not show the frequent occurrence of drizzle at high latitudes (poleward of $50^{\circ}$ ), suggesting that the altimeter measure in Fig. 6a is either sensitive to sea-ice, or is unreliable in high wind conditions. Chen et al. (2003) had previously noted such unrealistically large altimeter values at high latitudes, and overcome them by switching to a purely radiometer-based flag for mid-latitudes; Tournadre (2006b) developed his climatology by flagging data only passing both a 2 std dev. threshold and a radiometer (LWC) one. However, no radiometer flagging is incorporated here, because that adds a 
further subjective threshold, necessitates comparisons between the Jason-1 and Jason-2 radiometers, and also prevents passive microwave data being used as an independent source of evaluation data.

Zonal averages of the fraction of points deemed to be rain by the various tests show a wide disparity of values (Fig. 6c). The mean level of flagging depends very much on the choice of threshold; however both the selection of a backscatter measure and the associated threshold have an effect upon the latitudinal distribution. For AGC, the r.m.s. scatter about the mean relationship is around $0.25 \mathrm{~dB}$ (Fig. $3 \mathrm{c})$, therefore the percentage of altimeter data flagged according to the fixed $-0.5 \mathrm{~dB}$ or variable -2 std. dev. thresholds are very similar (Fig. 6c). For anomalies defined using the other measures of backscatter, the choice of a fixed or variable threshold does make a difference to the latitudinal distribution. This is because the wind conditions (and thus the background $\sigma_{C}^{0}$ ) vary latitudinally, and consequently so does the ability to detect light rain reliably. The additional dashed black line shows the proportion of time that drizzle is detected by AMSR during the same period. Most of the altimetric measures agree on the broad features, with a peak for the ITCZ around $5-10^{\circ} \mathrm{N}$, and a secondary peak at $10^{\circ} \mathrm{S}$; however several show unrealistically high values at high latitudes, and none of the others show the prominent peaks at $40-50^{\circ} \mathrm{S}$ and $40-50^{\circ} \mathrm{N}$ in AMSR that are associated with the mid-latitude storm tracks. Note, there is no fullyaccepted 'correct' zonal distribution, with even the two most widely accepted composite climatologies differing markedly in some regions [Béranger et al., 2006]. Part of the disparity between altimeter and AMSR detections will be due to AMSR responding preferentially to larger events (on account of its greater footprint size) and the altimeter flags generally being triggered at larger rain rates, and so not detecting drizzle.

Whilst there are broad spatial patterns in common between Figs. $6 \mathrm{a}$ and $6 \mathrm{~b}$, the magnitudes differ noticeably, with AMSR showing a slightly greater frequency of rain in the tropics, and the altimetry in the extra-tropics. This change in relative magnitudes is borne out by conducting simple linear regression in $10^{\circ}$ bands (Fig. 6d). A measure of the overall correspondence between the different records is determined via a regression including a latitudinal term:

$$
\mathrm{f}_{\mathrm{alt}}=\mathrm{g} \mathrm{f}_{\mathrm{AMSR}}(1+\mathrm{h} \cos \phi)+\mathrm{k}
$$

where $f_{\text {alt }}$ and $f_{\text {AMSR }}$ are the fractions of time raining in each $2.5^{\circ} \times 2.5^{\circ}$ box according to the Jason-2 altimeter and AMSR respectively, constant $g$ allows for the different detection thresholds implemented and $h$ models a dependence on latitude, $\phi$, due to changes in the height of the rain column. [This simple formulation permits a rough comparison of rain occurrences without the explicit need to calculate rain rates, as even the appropriate constants for such a calculation are subject to some debate.]

Although the fraction of data flagged by these tests varies between $1.0 \%$ and $9.2 \%$, the correlation of the geographical patterns with AMSR varies only between 0.24 and 0.58 (see Table 3 ). The use of a fixed threshold of $-0.5 \mathrm{~dB}$ flags far fewer points than the 2 std. dev. criterion (apart from for AGC, discussed earlier); however these detections of more pronounced rain rates are in better agreement with the AMSR patterns. The use of a lower fixed threshold $(-0.3 \mathrm{~dB})$ similarly flags more points but reduces the match with AMSR. Of the measures considered, anomalies calculated using $\sigma^{0}$ ice give the best match to AMSR data, whilst the performance of both the original $\sigma^{0}$ and the adjusted $\sigma_{\text {adj }}^{0}$ reduce markedly when the 2 std. dev. threshold is used instead of the fixed $-0.5 \mathrm{~dB}$ one.

\subsection{Consistency between Jason-1 and Jason-2}

As part of the requirement for constructing a multi-altimeter rain climatology there must be a good match between Jason-1 and Jason-2 records of rain. The $\sigma^{0}$ ice measure has not been implemented in the routine Jason-1 processing so that cannot be compared. The acquisition mode for Jason-1 is identical to that for Jason-2 during the first 15 days of operation, so the mean relation for Jason-1 AGC values is like that illustrated for Jason-2 during cycle 000. However, as the aim here is to test for consistent Jason-1/2 flagging during normal operations, the evaluation is over the later Jason-2 cycles, when the mean AGC_Ku vs. AGC_C relationships for the two altimeters have very different shapes. The standard $\sigma^{0}$ values for Jason-2 have exact counterparts in Jason-1, with the same waveform-fitting algorithm being used. The definition of $\sigma_{\text {adj }}^{0}$ for Jason-1 needs some amendment from that used for Jason-2 (eq. 1). 
There is considerable long-term mispointing for Jason-1, which varies along tracks and between cycles of data. Thus eq. 1 has to use a 140-second running mean of $\psi^{2}$ to provide the reference value $\psi^{2}$ lo and apply a second correction for the effect of the long-term variation in $\psi^{2}$, viz:

$$
\sigma_{\text {adj }}^{0}=\sigma^{0}-\alpha\left(\psi^{2}-\psi_{\text {lo }}^{2}\right)-\beta \psi_{\text {lo }}^{2}
$$

where the pertinent coefficients are detailed in Quartly [2009b].

For the comparisons I use nearly six months of data from Jason-2 cycles 002-020 (Jason-1 cycles 241-259). Jason-2 cycles 000 and 001 are avoided because of the different initial acquisition mode, which affects the AGC performance markedly; Jason-1 data were unavailable for most of cycle 243. There are $1 \mathrm{~Hz}$ values for $\sigma^{0}, \mathrm{AGC}$ and $\psi^{2}$ available on the GDRs; however, here I have regrouped the original $20 \mathrm{~Hz}$ Jason-2 data in groups of 20 nearest to the latitudes of the Jason- $11 \mathrm{~Hz}$ data, and then averaged these ensembles. This results in $1 \mathrm{~Hz}$ averages coinciding even more closely with the nominal average locations of the Jason-1 observations. This reduces the along-track displacement between Jason1 and Jason-2 observations to no more than $150 \mathrm{~m}$, although at times the across-track displacement may get to $1 \mathrm{~km}$. Given that $\sigma^{0}$ observations correspond to a measurement over the full altimetric footprint of $\sim 12 \mathrm{~km}$ diameter, these two altimeter's records of backscatter and attenuation may be regarded as coincident.

Quartly [2009b] has already shown that the adjustment process of Eq. 3 reduces the mismatch of $\sigma_{\mathrm{Ku}}^{0}$ observations by a factor of three (with a small reduction for $\sigma_{\mathrm{C}}^{0}$ ). Figure $3 \mathrm{~d}$ shows the comparison for the derived attenuation. The improvement by using $\sigma_{\text {adj }}^{0}$ is again clear, as is the increased mismatch for AGC compared with the original $\sigma^{0}$ values.

\subsection{Efficacy at data flagging}

The altimeter parameters of greatest interest to the general users are the wave height, the range and the backscatter strength, with considerable care taken to excise those data believed contaminated in any way. There is no universally-accepted set of data-quality tests, as those interested in coastal studies have to make use of data close to land, whilst those looking at storms are required to use observations when the LWC and associated corrections are high. However, a common part of such testing procedures is to examine the uncertainty (r.m.s. variability of the 20 records contributing to the individual $1 \mathrm{~Hz}$ value). Here I look at the uncertainties in these three main parameters of interest as a function of wave height $\left(\mathrm{H}_{\mathrm{s}}\right)$, because that value has the greatest effect upon the shape of the waveform, and thus on the reliability of the geophysical retrievals. The contour plots in Fig. 7 show 2-D histograms of uncertainty and $\mathrm{H}_{\mathrm{s}}$, with solid black lines showing the mean relationship for all data. There is clearly a greater density of observations around a wave height of $2 \mathrm{~m}$, and the mean uncertainties in wave height and range increase with $\mathrm{H}_{\mathrm{s}}$. The mean uncertainty in $\sigma^{0}$ remains constant for wave heights of $2 \mathrm{~m}$ or more (Fig. 7c) and increases slightly for $\mathrm{H}_{\mathrm{s}}<1 \mathrm{~m}$. This would tend to correspond to regions of very low winds (high $\sigma^{0}$ ) where the variability in $\psi^{2}$ is much greater (Fig. 5), with impact on the unadjusted parameter $\sigma^{0}$.

Each of the measures of backscatter strength was used in turn to define a sigma0 anomaly (departure of peak from mean $\mathrm{K}_{\mathrm{u}}-\mathrm{C}$ relationship) and those corresponding to a derived attenuation of below $-0.5 \mathrm{~dB}$ regarded as "rain-affected". The coloured lines in Fig. 7 show the mean properties of these flagged data. In general, the red and green lines $\left(\sigma^{0}\right.$ and AGC) lie close to the main black one, indicating that the data selected according to such a rain flag have uncertainties typical of all points. These two measures do show some skill (i.e. ability to select the more extreme values) by the preferential selection of points where $\sigma^{0}$ is more uncertain than average. However, for all three parameters, flagging with either $\sigma_{\text {ice }}^{0}$ or $\sigma_{\text {adj }}^{0}$ does a much better job of selecting points where the uncertainty is greater than average. Flagging using $\sigma_{\text {adj }}^{0}$ selects fewer points than using $\sigma_{\text {ice, }}^{0}$, but those selected according to $\sigma_{\text {adj }}^{0}$ correspond to those further from the normal uncertainties than those flagged by $\sigma^{0}{ }_{\text {ice. }}$. 


\section{Spatiotemporal variability of rainfall}

This six-month period of nearly simultaneous rain attenuation data from Jason-1 and Jason-2 affords a wonderful opportunity to review the results of Tournadre and Bhandari [2009], hereafter TB09, contrasting the spatial and temporal scales of rain variability. For their analysis they used data from TOPEX and Jason-1 during December 2002 to August 2003. The data analysed here are from a different half of the year, but it is expected that the underlying physical processes governing the scales of variability will be roughly similar (although the phase of the monsoon, for example, does differ). The main advantage for the Jason-1/2 analysis is that the instruments are very similar, with almost identical processing, hopefully permitting a more robust analysis. Here, I stick exclusively to the measure $\sigma_{\text {adj }}^{0}$, as it has been shown to give the closest correspondence between Jason-1 and Jason-2 both for measures simply of backscatter [Quartly, 2009b], and for derived attenuation (Fig. 3d).

Data are selected if both a point and its immediate successor have valid Jason-1 and Jason-2 data at both frequencies, and valid LWC data are available from the microwave radiometer on Jason-2. Spatial differences, denoted by $\delta_{\mathrm{x}}$ preceding the variable, are calculated between consecutive 1-sec points i.e. approximately $5.6 \mathrm{~km}$ along track. Temporal differences, denoted by $\delta_{\mathrm{t}}$, are between Jason- 1 and Jason-2 observations, which are $55 \mathrm{~s}$ apart. (This is slightly different to the TOPEX/Jason-1 separation of $72 \mathrm{~s}$.)

The r.m.s. values of the spatial and temporal differences are given in Table 4. The r.m.s. spatial differences for Jason-1 and Jason-2 are very similar, which is not surprising given their common design and processing. The values here for Jason-1 are $20 \%$ less than found by TB09 (their Table 2), which were less than the values noted for TOPEX. In fact for the most common wind conditions, the alongtrack differences at $\mathrm{K}_{\mathrm{u}^{-}}$and $\mathrm{C}$-band are both below $0.1 \mathrm{~dB}$, with greatest spatial variability associated with the extremes of $\sigma^{0}$ (see Figs. 8a and 8b). Values of $\sigma^{0}$ adj exceeding $20 \mathrm{~dB}$ are rare, but are associated with high spatial gradients, and greater scatter in dual-frequency comparisons (Fig. 3c). The typical spatial changes in backscatter and attenuation are, not surprisingly, greater in areas associated with rain (Table 4), but the magnitude of the increase will depend upon how rain-affected data are selected e.g. variations are greater for a higher LWC threshold or if altimeter measurements are part of the definition.

The temporal changes between Jason-1 and Jason-2 observations are approximately $50 \%$ of that noted between Jason-1 and TOPEX (TB09). This suggests that despite the best endeavours of those authors a considerable part of their temporal changes were due to the difficulties of comparing slightly different altimeters. At both frequencies the temporal change is greatest at the rare conditions of very high $\sigma^{0}$, with the differences more pronounced at $\mathrm{K}_{\mathrm{u}}$-band. TB09 agree that the temporal change at Cband is less than at $\mathrm{K}_{\mathrm{u}}$-band for $\sigma_{\mathrm{C}}^{0}<16 \mathrm{~dB}$, which corresponds to the majority of the data, but find Cband to have the greatest changes in very low winds (Fig. 8b of TB09). As one might expect the longer wavelengths that cause $\mathrm{C}$-band scattering to be less changeable, it is likely that their results were affected by the differences in instrumental construction/processing.

It is interesting that not only is the r.m.s. of $\delta_{t} A$ close to the r.m.s. of $\delta_{x} A$, but also that they show the same variation with wind conditions (Fig. 8c), whereas at high $\sigma^{0}$ the $\mathrm{K}_{\mathrm{u}^{-}}$and C-band measures individually show much greater spatial changes than the temporal ones. The geographical distributions of these features is explored in the right hand panels of Fig. 8, which are calculated only for those points deemed rain by the passive microwave measurements. The typical spatial gradients are $\sim 2.5$ times greater in the heavy rain areas of the ITCZ and the South Pacific Convergence Zone (SPCZ) than at midlatitudes or on the borders of the marine deserts (Fig. 8d). The temporal changes (Fig. 8e) typically vary a factor of 1.6 between the tropics and mid-latitudes, but do not show the same west-east differences within individual ocean basins. Thus within an ocean basin, those parts with the highest rain rates have the greatest spatial gradients, but the change with time is more homogeneous. This difference in gradients is emphasised in Fig. 8f, which suggests that the pattern is strongly influenced by the relative mix of stratiform and convective rain (cf. Fig. 14 of TB09). 


\section{Summary and conclusions}

Dual-frequency backscatter measurements have long been used to provide a means of generating a rain flag for altimeter data, both to act as an editing criterion (leaving only high quality data for sea surface height studies) and also for precipitation studies (both for individual investigations of storms and for generating global statistics on rainfall). Originally the measure used was simply the normalised backscatter estimate, $\sigma^{0}$, but the change in routine processing for Jason-1 to include mispointing [Amarouche et al., 2004] led to significant short-scale variability in $\sigma^{0}$. Consequently, it was proposed that AGC be used [Tournadre, 2006a] and that become the adopted method for Jason-2 [CNES, 2009] despite it not being an actual physical measure. Recently Quartly [2009a,b] developed 'adjustments' to the standard $\sigma^{0}$ values to compensate for the effects of mispointing, yielding a measure $\sigma_{\text {adj }}^{0}$ that showed a much greater consistency between the Jason-1 and Jason-2 altimeters. The data streams for the Jason-2 altimeter also include another variant, $\sigma^{0}$ ice, corresponding to the backscatter estimate according to a seaice model, but applied to all the waveform data whether or not over ice. This paper has constructed rainflagging algorithms using all four different measures $\left(\sigma^{0}, A G C, \sigma_{\text {ice }}^{0}\right.$ and $\left.\sigma_{\text {adj }}^{0}\right)$ and has considered their usefulness in terms of i) smoothness of mean relationship (and hence ease of implementation), ii) internal consistency, iii) narrowness of the dual-frequency relationship for rain-free data, iv) correspondence with other rain data, v) consistency between Jason-1 and Jason-2, and vi) efficacy at highlighting low-quality altimeter data.

As the AGC is an altimeter setting rather than a measured response from the ocean surface, its probability distribution is not necessarily unimodal, and the behaviour at $\mathrm{K}_{\mathrm{u}^{-}}$and $\mathrm{C}$-band may be connected and can vary with different modes of operation. Jason-2's initial mode, 'split gate tracker', led to smoothly varying distributions for both $\mathrm{K}_{\mathrm{u}^{-}}$and C-band AGCs, with a smooth mean relationship between the two, as for Jason-1 AGC values (not shown). However, the main two modes of Jason-2 operation, 'median tracker' and 'DIODE/DEM' produce a much more complicated relationship between the values at the two frequencies. The other three records of signal strength all show a smooth relationship, which is much more easily tabulated for implementation in the processing chain. However, a complicated mean relationship could be tolerated if its description remained fixed.

The second panel of Fig. 3 shows that the r.m.s. variability between cycles is also large and complex for AGC, such that it would have to be evaluated on a frequent basis. The inter-cycle variability is generally small for the other measures, with the standard measure $\sigma^{0}$ showing a little more inter-cycle variability at very low winds than is the case for $\sigma^{0}$ ice and $\sigma_{\text {adj. }}^{0}$ The intra-cycle variability (Fig. 3c) is important when considering what strength rain features will be clearly discernible above the general 'noise' in the relationship. Again $\sigma_{\text {ice }}^{0}$ and $\sigma^{0}$ adj show the least variability. Finally, in terms of consistency checks, there is the comparison of Jason-1 and Jason-2 records during their tandem phase. Unfortunately the measure $\sigma_{\text {ice }}^{0}$ is not available in the Jason- 1 product. The adjusted measure, $\sigma_{\text {adj, shows superior }}^{0}$ behaviour in this test to both $\sigma^{0}$ or AGC. (In the case of AGC, the comparison is complicated by the fact that the two instruments are operating in different acquisition modes.)

Some dual-frequency rain-flagging algorithms have included on-board radiometry as part of the test. By eschewing such an approach, I can use the LWC records as part of the validation and interpretation of the observed sigma 0 anomalies. For the standard $\sigma^{0}$ measure there are a large number of positive anomalies (Figs. 4a and 4b), with the larger ones associated with high LWC values. Although surface freshwater slicks damping down capillary waves offer a plausible physical mechanism [Quartly et al., 1996; Chen et al., 1998], it is clearly apparent that such positive sigma0 anomalies are much less common in the processing of AGC, $\sigma_{\text {ice }}^{0}$ or $\sigma_{\text {adj }}^{0}$, implying that frequent observations of wave damping by rain are an artefact of this definition of $\sigma^{0}$. The tail of the distribution of negative sigma 0 anomalies for $\sigma_{\text {ice }}^{0}$ is larger than for $\sigma^{0}$ or $\sigma_{\text {adj }}^{0}$, suggesting that although $\sigma^{0}$ ice may prove a good measure for detecting rain, its interpretation as an estimate of path-integrated attenuation may be biased a little larger than for other methods. Altimeter estimates of rain rate have been used to study the increase in intensity of rain within the ITCZ during El Niño [Quartly et al., 2000]; to extend such studies to envelop long-term changes requires that the altimetric method gives consistent rain rate distributions across multiple 
altimeters. Altimeters and radiometers do respond to different properties of rain cells, and average over different regions; therefore an exact match between their rain records should not be expected. However, an attenuation of $-0.5 \mathrm{~dB}$ recorded using $\sigma_{\text {ice }}^{0}$ or $\sigma_{\text {adj }}^{0}$ matches high LWC values better than retrievals using the standard $\sigma^{0}$. However, at very low wind speeds (high $\sigma^{0}$ ) there are large variations in the scatter about the $\mathrm{K}_{\mathrm{u}}-\mathrm{C}$ relation (Fig. 3c) and the threshold for significant match up with LWC is much greater (Fig. 4h and Table 2).

The comparison to independent precipitation datasets is more problematic. Ideally the validation data would be at a fine resolution, completely accurate, and coinciding exactly in time. In practice none of these goals is routinely achievable on a global basis. There have been a number of papers [Cailliau and Zlotnicki, 2000; McMillan et al., 2002; Tran et al., 2005] looking at validation of dual-frequency rain-flagging algorithms; here I simply show a crude comparison of the fraction of time raining, using AMSR daily data spanning the period of the Jason-2 cycles 002-020. By this approach, the analysis is of the detection of rain, rather than being dependent upon the choice of constants to convert attenuation to rain arte (see Eq. 2 of Quartly et al. [1999]). The relationship between the occurrences of rain in the two datasets shows a strong latitudinal variation, which will be due to a combination of effects. First, the altimeter flagging will depend upon assumptions concerning the melting layer height, which have not been addressed here. Second, the size of rain events tends to vary latitudinally, and thus so will the ability of AMSR with its large footprint to detect them. Third, there are regional differences in the mix of convective and stratiform events, and passive microwave sensors such as AMSR respond differently to these. The best correspondences between the fractional occurrences of rain by altimeter and passive

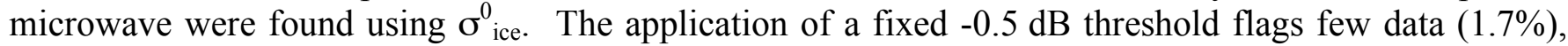
but gives the best correlation with the AMSR detection of drizzle. Of the flagging using the 2 std. dev. threshold, $\sigma_{\text {ice }}^{0}$ again gives the best match to AMSR, with $\sigma_{\text {adj }}^{0}$ performing surprisingly poorly.

Many users are not concerned with how well dual-frequency rain-flagging identifies true rain events, but at how well it does at enabling them to discard potentially suspect wave height or sea surface height data. The altimeter records include estimates of the uncertainty in $\mathrm{H}_{\mathrm{s}}, \mathrm{SSH}$ and $\sigma^{0}$, which are often used as a step in the data editing process. Figure 7 shows that editing according to attenuation derived from the standard $\sigma^{0}$ values discards data whose uncertainties are typical of the whole dataset, whilst the use of attenuation derived from the $\sigma_{\text {adj }}^{0}$ measure matches the more extreme and thus probably more suspect data points.

In many respects the measures $\sigma_{\text {adj }}^{0}$ and $\sigma^{0}$ ice are very alike; the former has an explicit adjustment for mispointing, $\psi^{2}$, determined empirically through investigation of the $20 \mathrm{~Hz}$ data [Quartly, 2009a], whereas the latter shows a simple bias with respect to $\sigma^{0}$ that is linear in $\psi^{2}$ (Fig. 2), but also shows some dependence on wave height (not shown). Both measures show minimal scatter about the mean relationship (Fig. 3c) and little variability between cycles (Fig. 3b). Neither is a standard $1 \mathrm{~Hz}$ product, but are easily produced; $\sigma_{\text {ice }}^{0}$ by averaging the 20 values per second, and $\sigma_{\text {adj }}^{0}$ by simple use of Eq. 1 and 3 (although obtaining a long-term mean, $\psi_{\text {lo }}^{2}$, is less straight-forward). The slightly narrower scatter of $\sigma_{\text {adj }}^{0}$ means that for a fixed threshold it flags fewer points (Table 3), and that those it does will match only the most extreme values of the uncertainty estimates (Fig. 7). However, in a simple comparison to the pattern of rain data according to AMSR, $\sigma^{0}$ ice gives the best performance (Table 3 ). The problem here is that AMSR does not necessarily provide a perfect unbiased reference, since PM sensors will preferentially record the larger rain cells.

This paper recommends altimetric rain-flagging to be performed using the measure $\sigma_{\text {adj }}^{0}$, since it usually gives the best performance, and is readily implemented in a consistent manner for both Jason-1 and Jason-2. The question of an appropriate threshold remains, with the fixed $-0.5 \mathrm{~dB}$ threshold flagging few data. The correct choice of a threshold may well vary with application, with $-0.5 \mathrm{~dB}$ being good for removing only the most contaminated altimetric records (Fig. 7), whereas the -2 std. dev. limit better matches the records of rain by the radiometer (Table 2 ). 
The correction advocated in Quartly [2009a] produces $\sigma_{\text {adj }}^{0}$ the backscatter value that would be produced by fitting a waveform model with $\psi^{2}=0$. The latest revision to the routine data processing at CLS is to retrack the waveform data with both a 4-parameter and a 3-parameter model (i.e. not fitting $\psi^{2}$, [P. Thibaut, pers. comm., 2009]), with the intention that $\sigma^{0}$ values from this latter model be used instead. Given the strong linear connection shown between $\sigma^{0}$ and $\psi^{2}$, this new retracking appears a long-winded approach to getting backscatter at $\psi^{2}=0$. It has been suggested that this reprocessing of the data may prove the more robust approach if the response function of the altimeter slowly degrades with time; however the coefficient, $\alpha$, is effectively determined by the chosen 4-parameter model and is easily reevaluated. Finally, the 3-parameter model is invalid for Jason-1, because of its genuine large $\left(>0.3^{\circ}\right)$ variations in platform attitude; however the full definition of $\sigma_{\text {adj }}^{0}$ (Eq. 3) also includes an adjustment for the long-period variations, enabling the quality of rain-flagging for Jason-1 to match that of Jason-2. Thus the full benefit of using $\sigma_{\text {adj }}^{0}$ looks unlikely to be equalled by this lengthy retracking initiative.

Further improvements to dual-frequency rain-flagging can be foreseen. The mean rain-free relationship between the sea surface roughness at the two different scales does vary a little with wave height (Fig. 3e). This effect, due to wind-sheltering by the larger waves [Elfouhaily et al., 1997] was characterised for both TOPEX [Quartly et al., 1999] and Jason-1 [Quartly, 2004], and could be modelled and incorporated within a new definition of attenuation. There also remain issues to be resolved concerning the conversions of attenuation estimates into rain rates, which has been avoided in this paper by concentrating on percentage of time raining. The appropriate attenuation coefficients will depend upon the size distribution of the raindrops and their temperature [Slack et al., 1994], and also the height of the rain column will be variable, although Tournadre [2006b] has developed estimates from on-board radiometers. At present, the calibration of the Jason-2 radiometer is still yet to be completed. Finally, Yang et al. [2008] noted that the presence of surface foam under large storms make the estimation of the attenuation due to rain more problematic, as both $\mathrm{K}_{\mathrm{u}^{-}}$and $\mathrm{C}$-band measures are affected. However, developing a consistency in rain detection and attenuation estimation for Jason-1 and Jason-2 is a major step toward the development of a consistent quantitative rain climatology spanning the two altimetric missions.

Lastly, section 5 has given an illustration of how the rain-flagging information from Jason-1 and Jason-2 may be combined to assess the temporal changes in rain rate. This section only briefly echoes the work of Tournadre and Bhandari [2009] indicating the potential for further work on this aspect. Fundamentally, it shows how some of those earlier results need to be re-assessed, given the much improved backscatter comparisons between the two altimeters in this tandem mission, with the temporal changes for the Jason-1/Jason-2 comparison only a half of those for the TOPEX/Jason-1 comparison. This has been due to i) both instruments having basically the same hardware and processing, whereas TB09 had to use TOPEX and Jason-1 data, ii) the improvements in quality and match-up of $\sigma^{0}$ data by Quartly [2009a,b], and iii) the $20 \mathrm{~Hz}$ Jason-2 data were here resampled to give $1 \mathrm{~Hz}$ averages more closely matching the Jason-1 locations (within $1 \mathrm{~km}$ ). However, a result consistent with TB09 is that the spatial gradients are greatest where the rain rate is greatest (Fig. 8d), whereas the temporal gradient is more zonally uniform (Fig. 8e). This illustration of the high repeatability of rain measurements by almost identical instruments a minute apart is of great reassurance to precipitation researchers using sensors on a suite of satellites (such as NASA's 'A Train'), which observe the same rain features minutes apart.

\section{Acknowledgements}

Jason-2 IGDR data were obtained from the CLS FTP server, under the OSTST-approved project 'TRIDENT II'. The author acknowledges the ongoing assistance from Pierre Thibaut in providing details of the routine processing applied to Jason data. 


\section{References}

Amarouche, L., P. Thibaut, O.-Z. Zanife, J.P. Dumont, P. Vincent, and N. Steunou (2004), Improving the Jason-1 ground tracking to better account for attitude effects, Mar. Geod., 27, 171-197.

Béranger, K., B. Barnier, S. Gulev, and M. Crépon (2006), Comparing 20 years of precipitation estimates from different sources over the world ocean, Ocean Dyn., 56, 104-138, doi:10.1007/s10236-0060065-2.

Cailliau, D., and V. Zlotnicki (2000), Precipitation detection by the TOPEX/Poseidon dual frequency radar altimeter, TOPEX Microwave Radiometer, Special Sensor Microwave/Imager and climatological shipboard reports, IEEE Trans. Geosci. Remote Sens, 38, 205-213.

Challenor, P.G., and M.A. Srokosz (1989), The extraction of geophysical parameters from radar altimeter returns from a non-linear sea surface, in Mathematics in Remote Sensing (ed. S.R. Brooks), Clarendon Press, Oxford, UK.

Chen G., B. Chapron, J. Tournadre, K. Katsaros, and D. Vandemark (1998), Identification of possible wave damping by rain using TOPEX and TMR data, Remote Sens. Environ. 63, 40-48.

Chen G., J. Ma, C. Fang, and Y. Han (2003), Global oceanic precipitation derived from TOPEX and TMR: Climatology and variability, J. Climate. 18 (23), 3888-3904.

CNES (2009), OSTM/Jason-2 Products Handbook, SALP-MU-M-OP-15815-CN, Issue 1 rev. 3, 67pp, 20th January 2009. Available at http://www.aviso.oceanobs.com/en/data/tools/aviso-userhandbooks/index.html

Ebert, E.E., and M.J. Manton (1998), Performance of satellite rainfall estimation algorithms during TOGA COARE, J. Atmos. Sci., 55, 1537-1557.

Elfouhaily, T., D. Vandemark, J. Gourrion, and B. Chapron (1998), Estimation of wind stress using dualfrequency TOPEX data, J. Geophys. Res., 103, 25101-25108.

Fu, L-L., E.J. Christensen, C.A. Yamarone Jr, M. Lefebvre, Y. Ménard, M. Dorrer, and P. Escudier (1994), TOPEX/POSEIDON mission overview, J. Geophys. Res., 99, 24369-24381.

Kummerow C. (1998), Beamfilling errors in passive microwave rainfall retrievals, J. Appl. Meteo. 37, 356-370.

Kummerow, C., W. Barnes, T. Kozu, J. Shiue, and J. Simpson (1998), The Tropical Rainfall Measuring Mission (TRMM) sensor package. J. Atmos. Oceanic Technol., 15, 809-817.

Lillibridge, J., R. Scharroo, and G. Quartly (2004), Rain and ice flagging of Envisat altimeter and MWR data. Proc. of Envisat and ERS Symposium, Salzburg, Austria, 6-10 September 2004, European Space Agency. Also available at: http://eprints.soton.ac.uk/17318

Marth, P. C., and coauthors (1993), Prelaunch performance of the NASA altimeter for the TOPEX/POSEIDON project. IEEE Trans. Geosci. Remote Sens., 31, 315-332.

McMillan, A.C., G.D. Quartly, M.A. Srokosz, and J. Tournadre (2002), Validation of the TOPEX rain algorithm: Comparison with ground-based radar. J. Geophys. Res., 107, 4038, doi:10.1029/2001JD000872.

Quartly, G.D. (1997), Achieving accurate altimetry across storms: Improved wind and wave estimates from C-band J. Atmos. Oceanic Technol. 14, 705-715.

Quartly, G.D. (1998), Determination of oceanic rain rate and rain cell structure from altimeter waveform data. Part I: Theory, J. Atmos. Oceanic Technol. 15, 1361-1378.

Quartly, G.D. (2004), Sea state and rain: A second take on dual-frequency altimetry, Mar. Geod. 27 (1-2), 133-152. \& 27 (3-4), 789-795.

Quartly, G.D. (2009a), Optimizing $\sigma^{0}$ information from the Jason-2 altimeter. IEEE Geosci. Remote Sens. Lett., 6, 398-402. doi: 10.1109/LGRS.2009.2013973.

Quartly, G.D. (2009b), Improving the intercalibration of $\sigma^{0}$ values for the Jason-1 and Jason-2 altimeters. IEEE Geosci. Remote Sens Lett., 6, 538-542. doi: 10.1109/LGRS.2009.2020921.

Quartly, G.D., and T.H. Guymer (2007), Realizing Envisat's potential for rain cloud studies, Geophys. Res. Lett. 34, art. no. L09807, doi:10.1029/2006GL028996.

Quartly, G.D., T.H. Guymer, and M.A. Srokosz (1996), The effects of rain on Topex radar altimeter data J. Atmos. Oceanic Tech. 13, 1209-1229.

Quartly, G.D., M.A. Srokosz, and T.H. Guymer (1999), Global precipitation statistics from dualfrequency TOPEX altimetry, J. Geophys. Res. 104, 31489-31516. 
Quartly, G.D., M.A. Srokosz, and T.H. Guymer (2000), Changes in oceanic precipitation during the 1997-98 El Niño, Geophys. Res. Lett., 27, 2293-2296.

Quartly, G.D., E.A. Kyte, M.A. Srokosz, and M.N. Tsimplis (2007), An intercomparison of global oceanic precipitation climatologies, J. Geophys Res., 112, D10121, doi:10.1029/2006JD007810.

Richards, F., and P.A. Arkin (1981), On the relationship between satellite-observed cloud cover and precipitation. Mon. Weather. Rev., 109, 1081-1093.

Tournadre, J. (1998), Determination of rain cell characteristics from the analysis of TOPEX altimeter echo waveforms, J. Atmos. Oceanic Tech. 15 (2), 387-406.

Tournadre, J. (2004), Validation of Jason and Envisat altimeter dual-frequency rain flags, Mar. Geod. 27, 153-169.

Tournadre, J. (2006a), Rain flag modification for version B Jason GDRs, Tech. Doc. DOPS/LOS 2006-01 v1.0, Ifrerner, BP 70, 29280, Plouznne. France, 19pp. (available at http://www.ifremer.fr/los/programmes/precipitations/pdfs/RAINFLAGB.pdf )

Tournadre, J. (2006b), Improved level-3 oceanic rainfall retrieval from dual-frequency spaceborne radar altimeter systems, J. Atmos. Oceanic Technol. 23, 1131-1149.

Tournadre, J., and S. Bhandari (2009), Analysis of short space-time-scale variability of oceanic rain using TOPEX/Jason, J. Atmos. Oceanic Technol. 26, 74-90.

Tournadre, J., and J. C. Morland (1997), The effects of rain on TOPEX/Poseidon altimeter data. IEEE Trans. Geosci. Remote Sens., 35, 1117-1135.

Tournadre, J., J. Lambin-Artru, and N. Steunou (2009), Cloud and rain effects on ALTIKA/SARAL Ka band radar altimeter. Part II: Definition of a rain/cloud flag, IEEE Trans. Geosci. Remote Sens. 47, 1818-1826. doi: 10.1109/TGRS.2008.2010127.

Tran N., E. Obligis, and F. Ferreira (2005), Comparison of two Jason-1 altimeter precipitation detection algorithms with rain estimates from the TRMM Microwave Imager, J. Atmos. Oceanic Technol. 22, 782-794.

Walsh, E.J., F.M. Monaldo, and J. Goldhirsh (1984), Rain and cloud effects on a satellite dual-frequency radar altimeter system operating at 13.5 and 35 GHz. IEEE Trans. Geosci. Remote Sens., 22, 615622.

Yang, L., J. Zou, M. Lin, and D. Pan (2008), Method to correct both foam and rain effects on dual frequency altimeter Jason1 wind measurements in typhoon Shanshan, Proc. of the SPIE vol. 7105, $71050 \mathrm{~L}-71050 \mathrm{~L}-12$. 
Table 1 : Mean values for each measure of Jason-2's signal strength for selected dataset. For remainder of paper, offsets are applied to measures 2-4 to give same mean as $\sigma^{0}$, and thus remove arbitrary offsets from plots

\begin{tabular}{|c|c|c|}
\hline $\begin{array}{c}\text { Measure of } \\
\text { backscatter }\end{array}$ & $\begin{array}{c}\mathrm{K}_{\mathrm{u}} \text {-band } \\
(\mathrm{dB})\end{array}$ & $\begin{array}{c}\text { C-band } \\
(\mathrm{dB})\end{array}$ \\
\hline$\sigma^{0}$ & 13.95 & 15.55 \\
\hline $\mathrm{AGC}$ & 25.29 & 17.19 \\
\hline$\sigma_{\text {ice }}^{0}$ & 12.84 & 16.04 \\
\hline$\sigma_{\text {adj }}^{0}$ & 13.95 & 15.55 \\
\hline
\end{tabular}

Table 2 : Threshold for a good match between altimetric and radiometric rain-flagging. Data within $0.25 \mathrm{~dB}$ of nominal $\sigma_{\text {adj }}^{0}$ value are used to calculate a standard deviation of the sigma 0 anomaly, and the anomaly range noted for which at least $50 \%$ of LWC values $\geq 0.4 \mathrm{~kg} \mathrm{~m}^{-2}$.

\begin{tabular}{|c|c|c|}
\hline$\sigma^{0}{ }_{\mathrm{C}}$ & s.d. $(\mathrm{dB})$ & $\begin{array}{c}\text { Threshold }(\mathrm{dB}) \\
\text { for 50\% match } \\
\text { with LWC }\end{array}$ \\
\hline 13.0 & 0.17 & -0.34 \\
\hline 13.5 & 0.18 & -0.40 \\
\hline 14.0 & 0.20 & -0.44 \\
\hline 14.5 & 0.19 & -0.46 \\
\hline 15.0 & 0.14 & -0.42 \\
\hline 15.5 & 0.12 & -0.32 \\
\hline 16.0 & 0.11 & -0.30 \\
\hline 16.5 & 0.12 & -0.32 \\
\hline 17.0 & 0.12 & -0.32 \\
\hline 17.5 & 0.14 & -0.34 \\
\hline 18.0 & 0.16 & -0.42 \\
\hline
\end{tabular}

Table 3 : Mean percentage of time raining according to each dual-frequency rain-flagging test, and its correlation $\left(\mathrm{r}^{2}\right)$ with the geographic pattern of light rain detected by AMSR. The correlation is for fitting using the model of Eq. 2 which allows for different overall rates and for a simple latitudinal dependence

\begin{tabular}{|c|c|c|c|c|c|c|}
\hline \multirow{2}{*}{$\begin{array}{c}\text { Measure of } \\
\text { backscatter }\end{array}$} & \multicolumn{2}{|c|}{$-0.5 \mathrm{~dB}$} & \multicolumn{2}{c|}{$-0.3 \mathrm{~dB}$} & \multicolumn{2}{c|}{-2 std. dev. } \\
\cline { 2 - 7 } & percentage & $\mathrm{r}^{2}$ & percentage & $\mathrm{r}^{2}$ & percentage & $\mathrm{r}^{2}$ \\
\hline$\sigma^{0}$ & $2.6 \%$ & 0.54 & $6.2 \%$ & 0.33 & $4.0 \%$ & 0.32 \\
\hline $\mathrm{AGC}$ & $4.7 \%$ & 0.42 & $9.2 \%$ & 0.41 & $4.3 \%$ & 0.44 \\
\hline$\sigma^{0}{ }_{\text {ice }}$ & $1.7 \%$ & 0.58 & $3.9 \%$ & 0.52 & $6.1 \%$ & 0.49 \\
\hline$\sigma_{\text {adj }}^{0}$ & $1.0 \%$ & 0.48 & $2.2 \%$ & 0.33 & $4.7 \%$ & 0.24 \\
\hline
\end{tabular}

Table 4 : Variability in backscatter $\left(\sigma_{\text {adj }}^{0}\right)$ and attenuation (A) measurements (in $\left.\mathrm{dB}\right)$. Categories marked 'rain' are for points for which $\mathrm{LWC} \geq 0.4 \mathrm{~kg} \mathrm{~m}^{-2}$.

\begin{tabular}{|c|c|c|c|}
\hline & $\begin{array}{c}\text { Spatial } \\
(\mathrm{J} 1)\end{array}$ & $\begin{array}{c}\text { Spatial } \\
(\mathrm{J} 2)\end{array}$ & Temporal \\
\hline $\mathrm{K}_{\mathrm{u}}$ (all) & 0.119 & 0.124 & $0.064^{*}$ \\
\hline $\mathrm{K}_{\mathrm{u}}$ (rain) & 0.253 & 0.255 & $0.102^{*}$ \\
\hline $\mathrm{C}$ (all) & 0.115 & 0.124 & $0.056^{*}$ \\
\hline $\mathrm{C}$ (rain) & 0.145 & 0.161 & $0.072^{*}$ \\
\hline A (all) & 0.065 & 0.074 & 0.083 \\
\hline A (rain) & 0.214 & 0.216 & 0.117 \\
\hline
\end{tabular}

* For inter-satellite comparisons, Jason-2 data are corrected for a slight bias and trend [Quartly, 2009b] before calculating differences. 


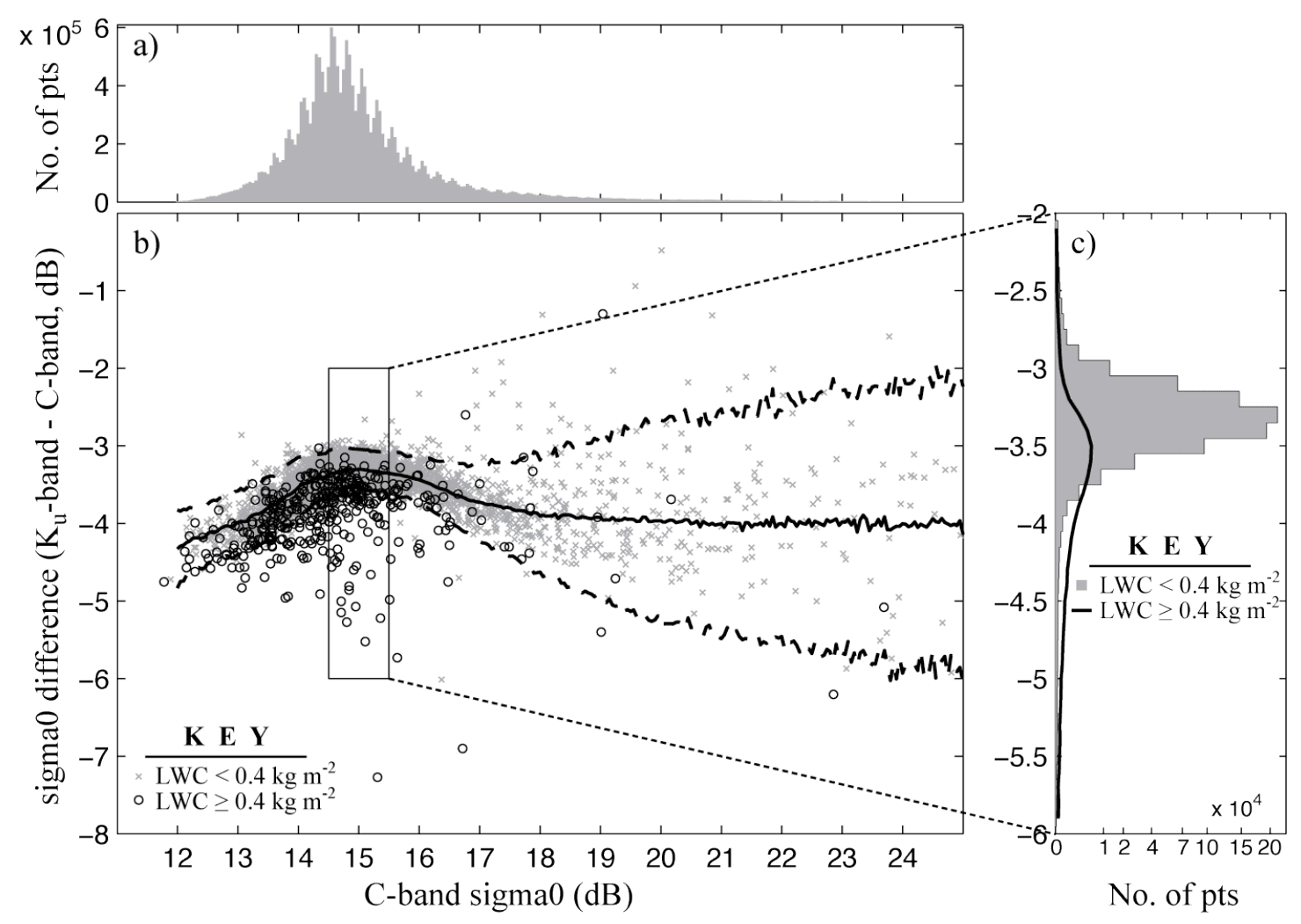

Fig. 1 : Historical example of simultaneous dual-frequency observations by the TOPEX altimeter during cycles 367-372. a) Histogram of the valid open ocean points $\left(2 \times 10^{6}\right)$, showing $90 \%$ have Cband $\sigma^{0}$ values between 13.4 and $18.4 \mathrm{~dB}$. b) Relationship between $\mathrm{K}_{\mathrm{u}^{-}}$and C-band values, with crosses for those with low LWC and circles for those with LWC $\geq 0.4 \mathrm{~kg} \mathrm{~m}^{-2}$. The solid line marks the mean relationship, with the dashed lines indicating \pm 2 std. dev. calculated using all the data with LWC $<0.4 \mathrm{~kg} \mathrm{~m}^{-2}$. c) Histogram of $\sigma^{0}$ difference $\left(\mathrm{K}_{\mathrm{u}}-\mathrm{C}\right)$ for points with $\sigma_{\mathrm{C}}^{0}$ in the range 14.5 to $15.5 \mathrm{~dB}$ separated according to LWC value. (Note non-linear $\mathrm{x}$-axis to allow both histograms to be displayed.) 
a)
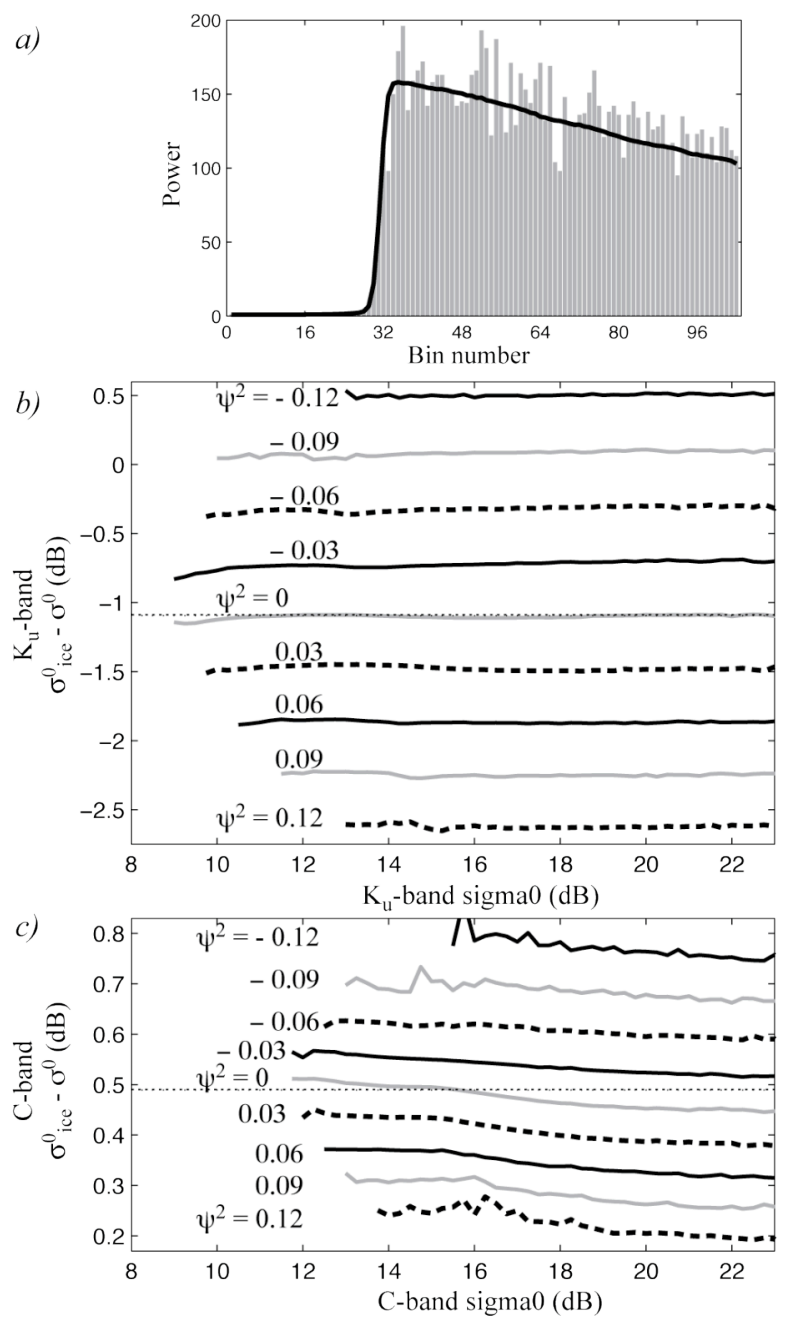

Fig. 2 : Definitions of $\sigma^{0}$ and $\sigma^{0}$ ice. a) Schematic showing a sample Jason-2 waveform (here averaged over $1 \mathrm{sec}$ ), plus fitted curve, which is used to infer $\sigma^{0}$. The definition of $\sigma^{0}$ ice is based on the ratio of the summations of the fourth and second powers of the signals in all the waveform bins [P. Thibaut, pers. comm. 2009]. b) Mean difference between the two definitions at $\mathrm{K}_{\mathrm{u}}$-band for various mispointing angles. c) Same for C-band.

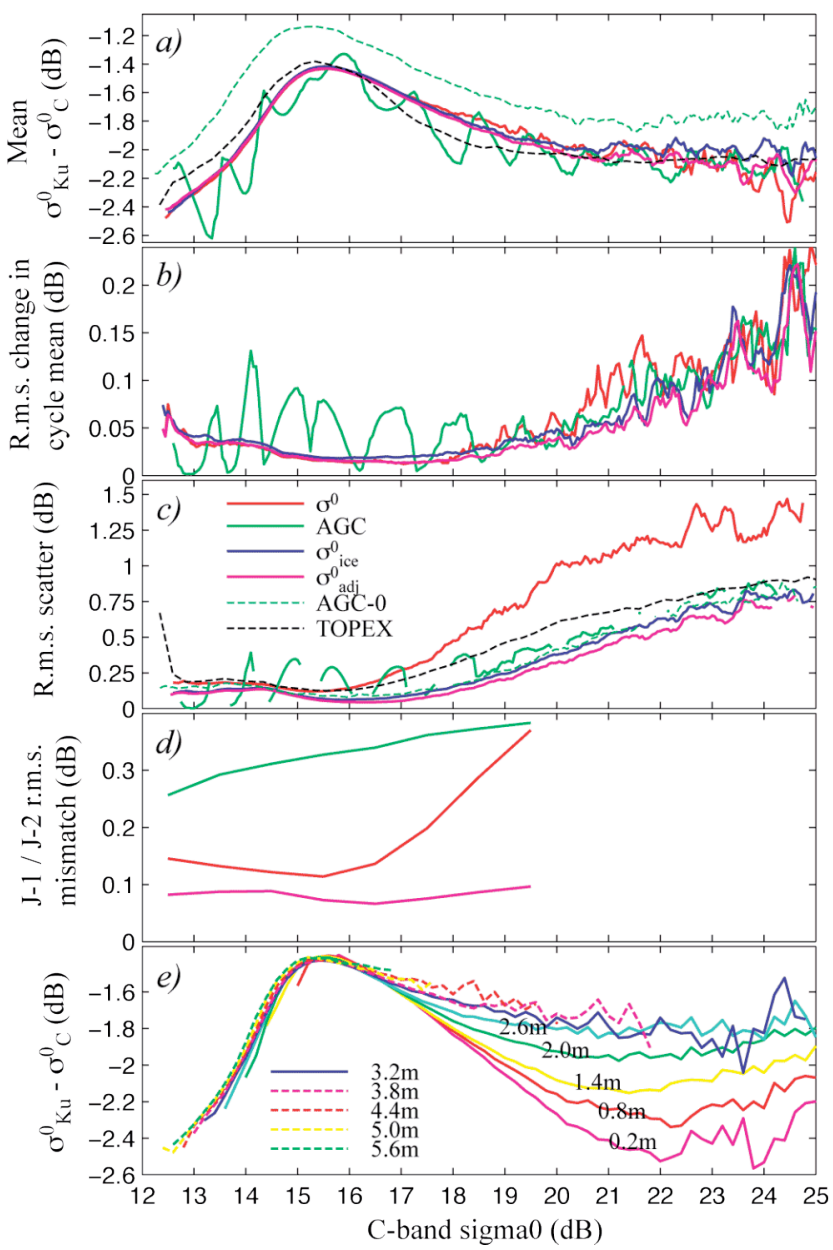

Fig. 3 : Characteristics of the dual-frequency relationships for the differing definitions of backscatter a) Mean relationship for given cycle. (Jason- 2 cycle 011 for all the solid lines; green dashed is AGC for cycle 000 and black dashed is TOPEX $\sigma^{0}$ for cycles 367-372.) b) R.m.s. change in mean between successive cycles (002 to 020). c) Scatter about mean relationship. d) R.m.s. difference between Jason-1 and Jason-2 estimates of attenuation. (Legend in third panel applies for first 4 panels.) e) Effect of wave height on mean relationship (only shown for $\sigma^{0}$ adj). 


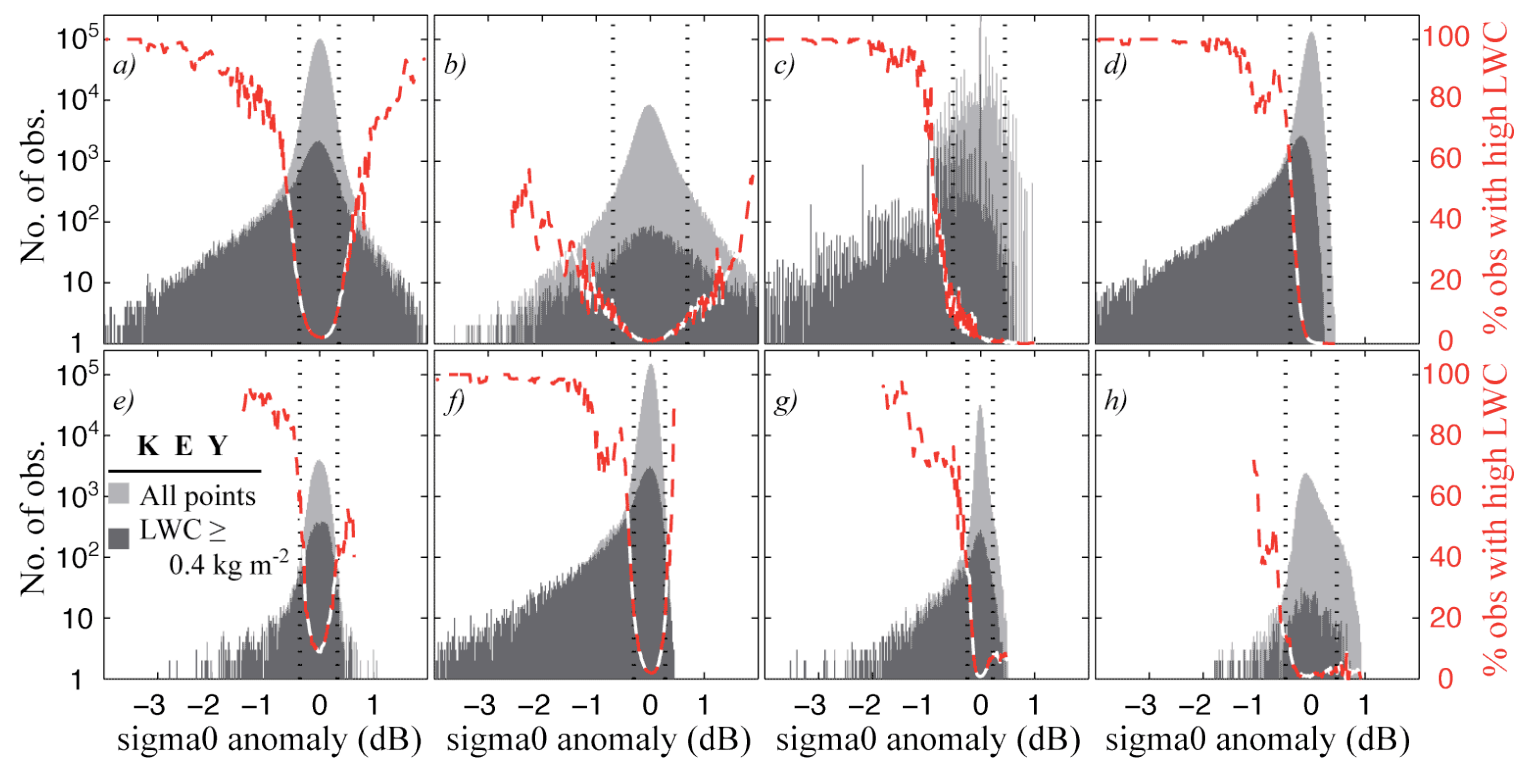

Fig. 4 : Histograms of sigm0 anomaly (if negative, corresponds to estimated attenuation) calculated for various wind conditions (range of $\sigma_{C}^{0}$ ) Light shading is for all points within $\pm 0.25 \mathrm{~dB}$ of stated $\sigma_{\mathrm{C}}^{0}$ value, dark shading for those likely to be associated with rain according to LWC, and the red dashed line shows the percentage of points in each bin associated with high LWC (see right-hand axes). Vertical dotted lines show \pm 2 std dev. of the sigma 0 anomaly (alternative to use of a fixed $-0.5 \mathrm{~dB}$ threshold for flagging). a) original $\sigma^{0}=13 \mathrm{~dB}, \mathrm{~b}$ ) original $\left.\left.\sigma^{0}=15 \mathrm{~dB}, \mathrm{c}\right) \mathrm{AGC}=15 \mathrm{~dB}, \mathrm{~d}\right) \sigma_{\text {ice }}^{0}=$ $15 \mathrm{~dB}$, e) $\sigma_{\text {adj }}^{0}=13 \mathrm{~dB}$, f) $\left.\left.\sigma_{\text {adj }}^{0}=15 \mathrm{~dB}, \mathrm{~g}\right) \sigma_{\text {adj }}^{0}=17 \mathrm{~dB}, \mathrm{~h}\right) \sigma_{\text {adj }}^{0}=19 \mathrm{~dB}$.

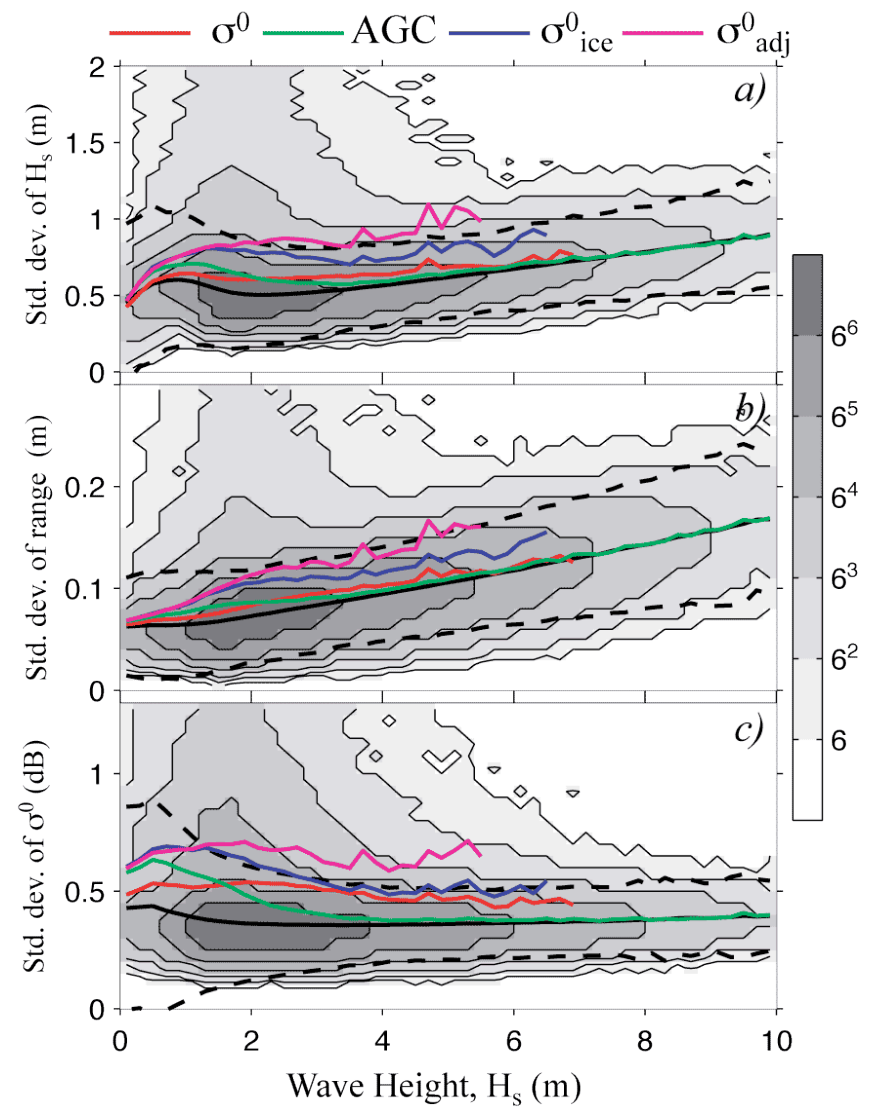

Fig. 7 : Efficacy of rain-flagging technique in detecting altimeter values with the greatest uncertainties. Underlying contour plots show two-dimensional histograms of wave height and uncertainty in a) wave height, b) range, and c) backscatter strength, with solid black lines indicating mean relationship, and dashed lines \pm 2 std. dev. The coloured lines show the mean relationship of those points flagged due to their derived attenuation being below $-0.5 \mathrm{~dB}$.

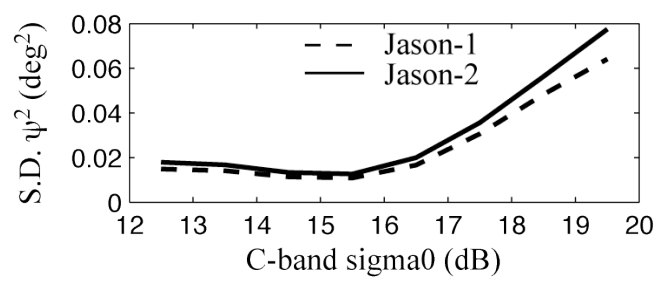

Fig. 5 : Variability in $\psi^{2}$ binned according to C-band backscatter strength $\left(\sigma^{0}\right)$. 

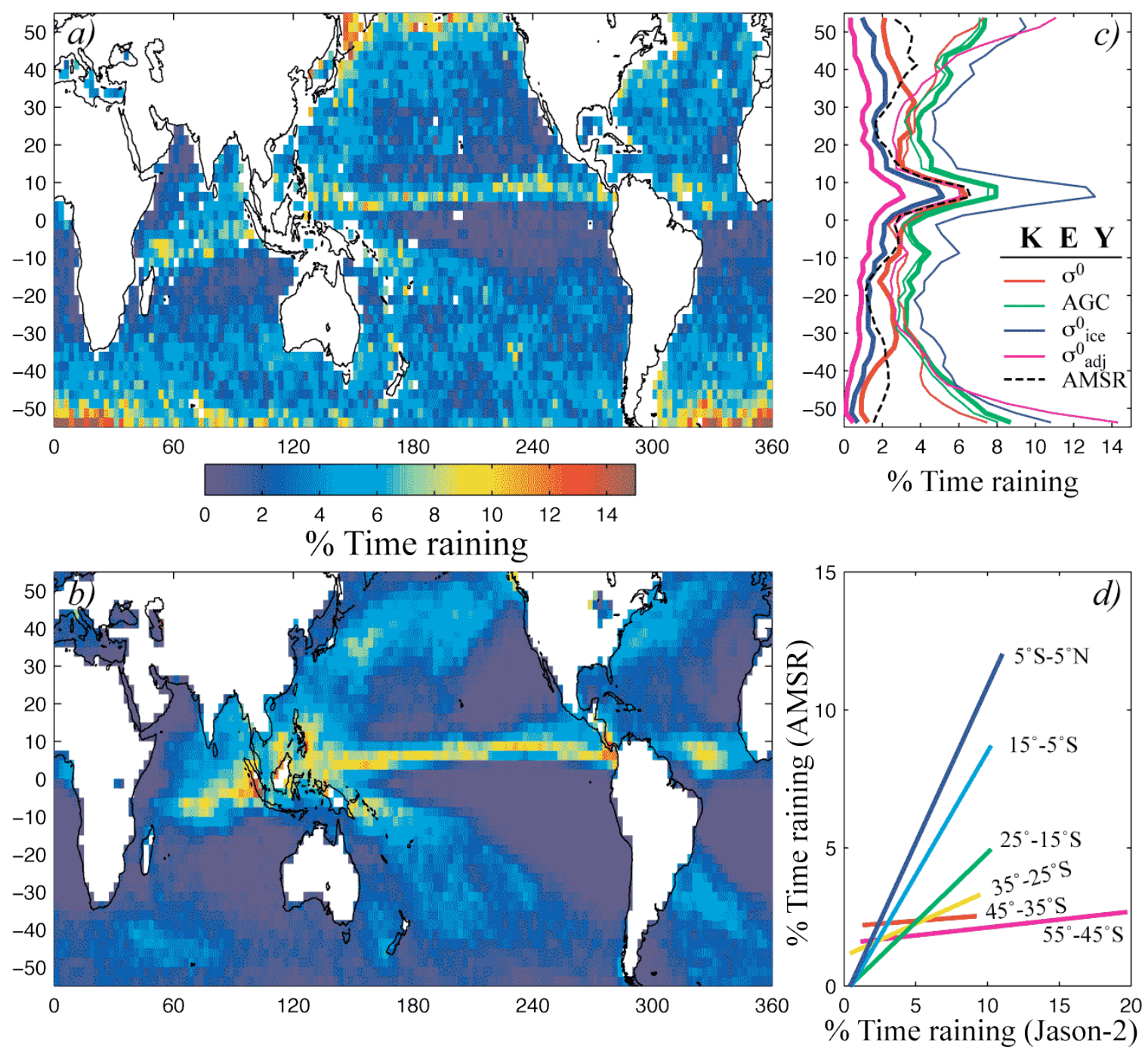

Fig. 6 : Percentage of time raining. a) Geographical pattern for flagging Jason-2 using anomaly based on $\sigma^{0}>2$ std. dev. b) AMSR data showing percentage of time with rain rates $>1 \mathrm{~mm} \mathrm{hr}^{-1}$. c) Latitudinal averages for multiple definitions and thresholds; thick lines represent flagging using $-0.5 \mathrm{~dB}$ threshold, thin lines are for 2 std. dev. d) Relationship between parts a) and b) by finding linear regression in $10^{\circ}$ latitude bands. 

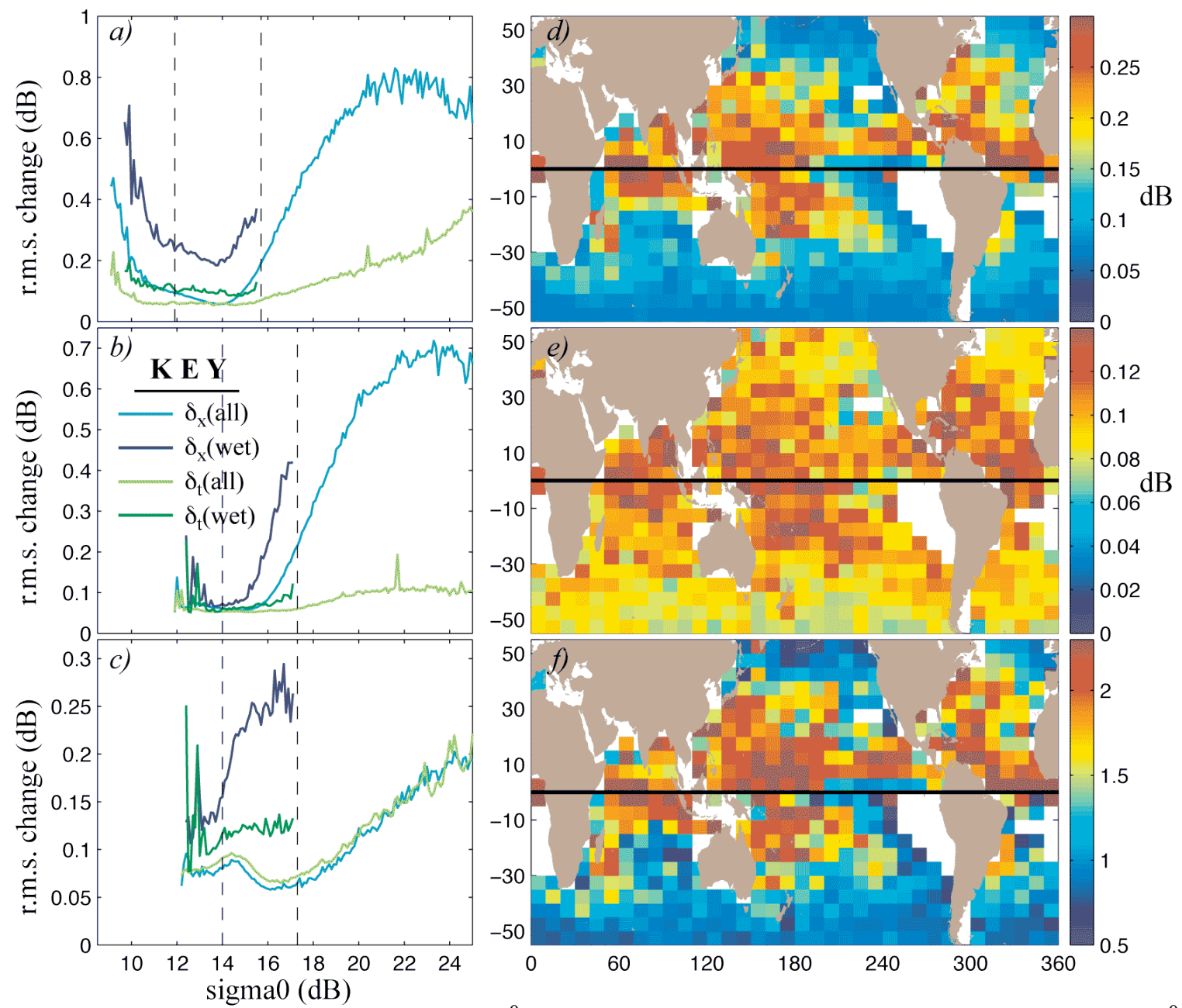

Fig. 8 : Spatial and temporal differences in $\sigma_{\text {adj }}^{0}$ and in derived attenuation, A. a) Changes in $\sigma_{\mathrm{Ku}}^{0}$ as a function of $\left.\sigma_{\mathrm{Ku}}^{0}, \mathrm{~b}\right)$ Changes in $\sigma_{C}^{0}$ as a function of $\sigma_{C}^{0}$, c) Changes in A as a function of $\sigma_{C}^{0}$. Blue curves are Jason-2 changes for $5.6 \mathrm{~km}$ (1 s) along track (curves are almost identical for Jason-1); green curves are for difference between altimeters $55 \mathrm{~s}$ apart. Darker lines are for those points also with LWC $\geq 0.4 \mathrm{~kg} \mathrm{~m}^{-2}$. Vertical lines denote the 5th and 95th percentiles of the $\sigma^{0}$ distribution. Right-hand panels show geographical variation of attenuation changes for events where LWC $\geq 0.4 \mathrm{~kg} \mathrm{~m}^{-2}$. d) $\delta_{x} \mathrm{~A}$ i.e. r.m.s. spatial change in A for $5.6 \mathrm{~km}$ along track, e) $\delta_{t} A$ i.e. r.m.s. temporal change in $A$ between altimeters $55 \mathrm{~s}$ apart, f) Ratio: $\delta_{\mathrm{x}} \mathrm{A} / \delta_{\mathrm{t}} \mathrm{A}$. 